\title{
Issues of Backhaul Construction Based on Long Term Evolution Technology
}

\author{
L. O. Tokar' ${ }^{1}$ Ya. O. Krasnozheniuk ${ }^{2}$ \\ Kharkiv National University of Radio Electronics, Kharkiv, Ukraine \\ Corresponding author. E-mail: liubov.tokar@nure.ua ${ }^{1}$,yana.krasnozheniuk@nure.ua²
}

Paper received 30.01.19; Accepted for publication 05.02.19.

\author{
https://doi.org/10.31174/SEND-NT2019-193VII23-12
}

\begin{abstract}
The packet-based infrastructure offers great opportunities for the organization of universal transport networks using LTE technology, which is associated with a wide variety of standards and applications as well as the use of various communication, management and maintenance protocols by modern networks. Issues related to the rational construction of a mobile transport infrastructure were considered for the organization of broadband access. Architecture for the backhaul network using a star configuration is proposed. the construction of the network in accordance with the concept of Unified MPLS is analyzed, at all levels of which a multiprotocol label switching protocol is configured to simultaneously support several generations of mobile communication in a single network plane-oriented architecture.
\end{abstract}

Keywords: backhaul, wireless technology, packet architecture, bandwidth.

1. Introduction. The rapid development of the information and communication industry dictates the need for new principles of system building. This is conditioned by the growth in the number of mobile users, the introduction of broadband wireless services and increased requirements for high-speed data networks.

Great opportunities are opening up when implementing wireless access technologies that use the packet data infrastructure. This approach will provide maximum expansion of IP protocol usage over the network.

LTE technology is a promising mobile broadband technology in terms of performance. Mobile operators will have the opportunity to increase network capacity and bandwidth together with high traffic transmission rates and lower packet transmission delays. Therefore, at present, many telecom operators are switching their backhauls to IP, based on the support of $3 \mathrm{G}$ traffic as well as to ensuring the quality and duration of communication with the Internet or $4 \mathrm{G}$ network.

The backhaul refers to the part of the network that is the link between the IP network and the core network. Backhaul takes the main burden of communication between the elements of the mobile access network and the operator's backbone network. This means that its role is to transport data from the mobile user to the switching capacity of the mobile operator and through it to other operators.

The essence of the study is to consider issues in the organization of the backhaul with the support of the full range of technologies and services using LTE technology. This determines the relevance of the given publication.

2. Brief overview of publications related to the subject. In terms of providing new high-speed user services, mobile operators face technical and economic difficulties. It is necessary to increase the capacity of the transport network, especially at the backhaul level.

The Wi-Fi IEEE 802.11n mobile communication standard has been proposed to be used not only in access networks, but also in backhauls [1]. This solution is associated with the need to obtain a sufficiently high throughput in the forward and reverse links. In addition, as a result of this approach, the performance of the backhaul will increase. However, such a network can successfully serve areas with relatively low population density and a small radius of action.
In [2], the issues faced by the modern information and communication society were addressed: the bandwidth deficit and a variety of high-speed mobile technologies. It is proposed to use an optical access platform for mobile backhauling in order to significantly reduce capital and operation costs.

In [3], one of the promising directions for constructing a heterogeneous HetNet backhaul is highlighted. The use of wireless solutions for backhauls operating in NLOS and LOS modes is proposed. However, the use of such systems in unlicensed frequency bands is considered to be too susceptible to interference, which may limit their use in backhauls. At the same time, lower bands have power limitations, which lead to low reliability of the connection or its loss.

As an alternative for mobile transport backhauls, Ethernet over PDH technology was considered in [4]. This solution will allow mobile operators to maximize the channel bands for their effective use. However, in order to reach the operator level using Ethernet technology, it is necessary to solve the issues of differentiation and prioritization of traffic with the specified mechanisms for ensuring quality of service.

It is known that LTE technology has significant improvements in the network architecture compared to $3 \mathrm{G}$ networks. In [5], the main LTE technology nodes are displayed with security features - secure access, network domain, user domain, application domain, 3GPP domain. This will ensure overall network security, which, together with minimal latency and flexible channel bandwidth, especially in the backbone part of the network, will attract consumers. In addition, in the context of network integration, user and application security issues are of primary importance.

3. Goal. The aim of the work is to consider the issues of building a backhaul. Given the current trends in the development of networks, the primary tasks are to implement the interaction of several generations of mobile communications in a single network architecture. This approach is necessary for telecom operators at the stage of a gradual transition from obsolete technologies to an IPplatform.

The backhaul takes the main burden of communication between the elements of the mobile access network and the operator's backbone network. Issues regarding the choice of topology for a fully connected backhaul and the 
choice of an adequate technology for building a network based on a flat packet-oriented architecture are relevant.

4. Materials and methods. Unlike mobile networks of previous generations, $4 \mathrm{G}$ networks fully rely on IP, which is associated with the development of the information and communication industry. The use of LTE technology using only IP simplifies network operation, which is extremely necessary for mobile operators. In addition, the creation of a flat packet architecture excludes individual devices from the network, such as controllers of the transport segment, which allows to directly connect to the packet core using the appropriate interfaces.

When deploying backhauls based on LTE technology, some compromises are reached by operators. On the one hand, the network must be scalable and high-quality, and on the other hand, the realities of the current network equipment require investing new IP-oriented networks.

For optimal construction of a backhaul, a rational choice is to use a star architecture. As a central node, it is better to choose a service core router. Thus, when data reaches the backbone of the network, the amount and priority of Internet traffic or server content is determined by mobile operators. This architecture allows to process several types of traffic.

The choice of this backhaul architecture will provide an effective combination of Layer 2 (L2) and Layer 3 (L3) according to the OSI model in the transport network, with L2 in the access area and L3 in the aggregation segment.
The interaction, roaming and handover of LTE and $2 \mathrm{G}$ / $3 \mathrm{G}$ networks can be carried out at the initial stage, taking into account the use of IP protocol that will support the work of various mobile nodes, which is reflected in the 3 GPP project [6]. The recommendations of the $3 \mathrm{GPP}$ project take into account the use of VPNs for L2, for L3 VPNs and gateways using VPN-based MPLS technology. Such a management system will provide economic support for scalable services and services in the IP network.

This approach reveals a number of attractive features: high performance and bandwidth, traffic modeling, ease of building networks and their operation.

The main incomes of mobile operators are generated through the provision of Ethernet, IP VPN, VoIP, IP video conferencing services to business clients, as well as through the provision of Triple Play, IPTV services to private consumers. Important in terms of revenues of mobile operators is the provision of the lease of its resources, i.e. this is mobile aggregation and retransmission with the provision of interaction at the core network level.

The architecture of such networks is determined by the basic elements: IP - mobile terminals and application systems. In addition, the necessary components between the terminals and the application server are base stations, traffic aggregation level and the Evolved Packet Core (EPC) [7].

A fragment of the transport network using MPLS technology while providing interaction at the reference level is shown in Fig. 1.

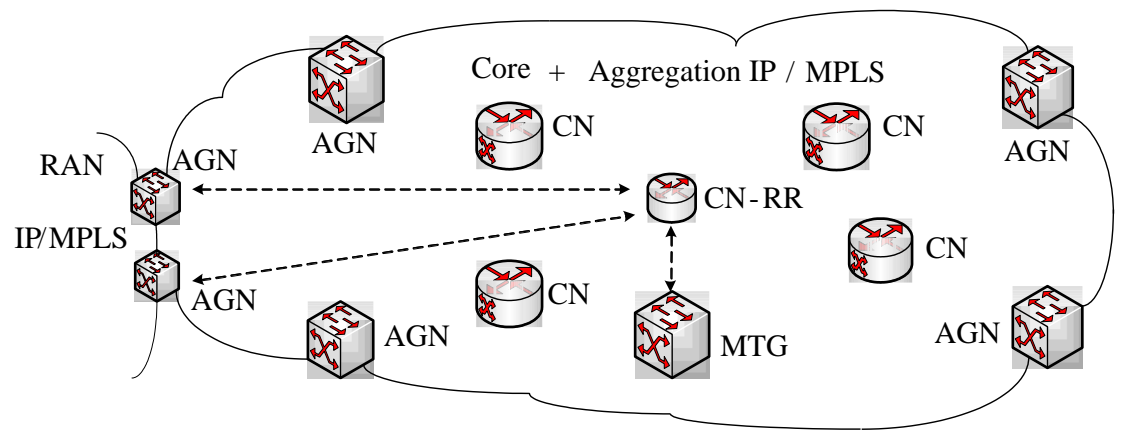

Figure 1 - A fragment of the transport network

In traditional MPLS technology, there are some difficulties associated with the complexity of implementing services in large networks. This, for example, requires the use of complex L3 mechanisms when interfacing with L2 protocols.

These disadvantages are absent in Unified MPLS, which will ensure high performance, bandwidth and ease of network operation. In addition, integrating access, aggregation and core segments using MPLS can reduce the number of administration nodes [8].

Thus, a single MPLS technology forms the transport basis for supporting LTE, $2 \mathrm{G} \mathrm{GSM}$ and $3 \mathrm{G}$ networks in the UMTS standard. The use of a single MPLS standard for mobile transport will provide operators with a comprehensive solution optimized in cost, with support for user traffic and business traffic with high rates of quality of service (QoS) compared to similar standards.

The operator's backhaul consists of three levels. At the access level, CSG nodes, the so-called pre-aggregation nodes, operate in the RAN domain. The aggregation and core levels are combined into one level - aggregation + core. The corresponding nodes are the aggregation nodes (AGN) and the core nodes (CN, CN-RR and MTG). This solution will simultaneously support several generations of mobile communications in a single converged network architecture, ensuring the introduction of LTE with Pseudowire Emulation support (PWE) for 2G GSM transmission, L2VPN for 3G UMTS / IP and L3VPN for 3G UMTS / IP. Combined aggregation and core levels into one level (Core + Aggregation) should be integrated into a single IGP / LDP domain.

6. Results and discussion. Thus, the issues of building an optimal construction of a backhaul based on the Unified MPLS concept are considered.

It should be noted that the use of MPLS technology allows implementation of both dynamic and static levels of network management. MPLS has the flexibility to support all types of NGN and traditional services. This contradicts with the practical data obtained in [9], the author of which cites the matrix of support for MPLS technology with Ethernet, Traditional and IP technologies according to key 
technical characteristics and main categories of network services.

The network management system must have information about the network topology. Due to the Unified MPLS architecture, End - to - End services are created by configuring only the end devices, which solves the problem of reducing the number of administration points.

The given paper shows the need to integrate the combined aggregation and core levels into a single IGP / LDP domain. This solution, in conjunction with the BGP protocol, is used to ensure high stability and fast network convergence.

Research results can be useful for creating a converged network scenario based on Fixed / Mobile Infrastructure (FMI).

The results of the work indicate a number of controversial issues regarding the appropriateness of using MPLS technology at all levels of the network. They relate to the problems of using mechanisms for improving the convergence of IGP protocols: IP / MPLS Loop Free Alternate Fast ReRoute (LFA FRR) and MPLS TE Fast ReRoute (TE FRR). The choice of these mechanisms should be due to the shortest network recovery time and ease of operation, which should contribute to the rapid convergence of the network without a complex configuration.

7. Conclusions. 1. It has been analyzed that for the optimal construction of the transport network, especially at the backhaul level, the use of various technologies and platforms is possible.

2. It is shown that LTE technology is the most promising technology of mobile broadband in terms of performance. The transition to the IP-platform will allow the operator to easily increase the bandwidth and provide new services.

3. The backhaul architecture is considered. It is shown that an adequate topology, the most relevant in the transition to high-speed LTE technology, as well as with a large increase in the number of users and services, is a starshaped configuration.

4. The feasibility of choosing MPLS technology to build a backhaul with the concept of Unified MPLS is analyzed, which is especially important in matters of network convergence to provide support for transport applications and services.

\section{REFERENCES}

1. Ксензенко, П. Я. Развитие сетей Backhaul [Текст] / П. Я Ксензенко, П. В. Химич // Телеком. - 2012. - № 11. - С. $28-38$.

2. Saranya, B., Muruganandham, S. Mobile Backhaul Network in wireless Sensor [Text] / B. Saranya, S. Muruganandham // International Journal of Engineering Research and General Science. - 2015. - vol. 3. - p. $394-397$.

3. Ксензенко, П. Я. Backhaul для гетерогенных сетей [Текст] / П. Я. Ксензенко, Т. Н. Нарытник // Телеком. - 2014. - № 1-2. - C. $10-21$.

4. Катлеров, П. Н. Ethernet over PDH: миграция к пакетной транспортной инфраструктуре беспроводных сетей [Текст] / П. Н. Катлеров // Компоненты и технологии. 2013. - № 10. - C. 116 - 120.

5. Masud, Md Mehedi. Survey of security features in LTE Handover Technology [Text] / Md Mehedi Masud // Scientific Research Journal (SCIRJ). -2015. - vol. 3. - p. 27 - 31.

6. 3GPP TS 45.005 V8.8.0 (2010-03) [Электронный ресурс] / 3rd Generation Partnership Project; Technical Specification
Group GSM/EDGE Radio Access Network; Radio transmission and reception (Release 8). - Режим доступа: http://www.qtc.jp/3GPP/Specs/GSM_GERAN/45005880.pdf. - 25.06.2016 г. - Загл. с экрана.

7. Cisco Visual Networking Index: Global Mobile Data Traffic Forecast Update [Электронный ресурс] / White Paper, February 3, $2016 . \quad-\quad$ Режим доступа: http://www.cisco.com/c/en/us/solutions/collateral/serviceprovider/visual-networking-index-vni/mobile-white-paperc11-520862.html. - 22.06.2016 г. - Загл. с экрана.

8. Коденцев, Д. Развитие платформ Cisco для MPLS доступа и преагрегации [Электронный ресурс] / CCIE. - Режим доступа: http://www.20161207-celc-sp-iosxe_v2_2.pdf. 17.12.2016 г. - Загл. с экрана.

9. Гасымов, И. Архитектура Cisco Unified MPLS [Электронный pecypc] / CCIE. - Режим доступа: http://www.20161207-celc-sp-iosxe_v2_2.pdf. - 17.12.2016 г. - Загл. с экрана.

\section{REFERENCES}

1. Ksenzenko, P. Ya., Himich, P. V. (2012). Razvitie setey Backhaul. Telekom, 11, $28-38$.

3. Ksenzenko, P. Ya., Naryitnik, T. N. (2014). Backhaul dlya geterogennyih setey. Telekom, 1-2, $10-21$.

4. Katlerov, P. N. (2013). Ethernet over PDH: migratsiya k paketnoy transportnoy infrastrukture besprovodnyih setey. Komponentyi i tehnologii, 10, 116 - 120 .
8. Kodentsev, D. (2016). Razvitie platform Cisco dlya MPLS dostupa i preagregatsii. CCIE. Available at: http://www.20161207-celc-sp-iosxe_v2_2.pdf.

9. Gasyimov, I. (2016). Arhitektura Cisco Unified MPLS i. CCIE. Available at: http://www.20161207-celc-spiosxe_v2_2.pdf. 